\title{
The Impact of DNMT3A/FLT3-ITD/NPM1 on Patients with Acute Myeloid Leukemia after Allogeneic Hematopoietic Stem Cell Transplantation
}

\author{
Akut Myeloid Lösemili Hastalarda DNMT3A/FLT3-ITD/NPM1'in Allojeneik Hematopoetik Kök \\ Hücre Transplantasyonu Sonrası Etkisi
}

(D) Long Su

Jilin University First Hospital, Clinic of Hematology, Changchun, China

To the Editor,

Recently, Ardestani et al. [1] published their excellent findings in this journal. They found that DNMT3A mutations alone do not affect the clinical outcomes of acute myeloid leukemia (AML) patients undergoing allogeneic hematopoietic stem cell transplantation (allo-HSCT), but when accompanied by FLT3-ITD mutations, the overall survival (OS) was significantly reduced and the relapse rate increased. NPM1 mutations had no impact on either relapse-free survival or $\mathrm{OS}$, but there was a significant difference between AML patients with and without NPM1 mutations for relapse [1].

Integrative genomic analysis of de novo AML identified a subset of AML patients in which DNMT3A, FLT3, and NPM1 mutations coexisted at a higher frequency than would be expected from chance occurrence [2]. Our unpublished data also showed that a close association could be observed among DNMT3A, FLT3, and NPM1 mutations in patients with AML by factor analysis $(p<0.05)$ based on 357 de novo AML patients analyzed by next-generation sequencing. A previous study demonstrated that younger ( $<60$ years) patients with DNMT3A/FLT3/NPM1 mutations had significantly shorter event-free survival $(p=0.047)$ and a tendency towards shorter OS ( $p=0.095)$ compared to those in other mutation groups [3]. The adverse impact of DNMT3A mutations is more pronounced than that of FLT3-ITD among patients with NPM1 mutations [3]. Accordingly, how did DNMT3A/FLT3-ITD/NPM1 triple mutations influence the prognoses of AML patients who underwent allo-HSCT in this study? What about the impact of DNMT3A or FLT3-ITD on NPM1-mutated AML patients? Recent studies reported that variant allele frequencies of the NPM1 and FLT3-ITD genes were closely related to long-term outcomes in patients with AML $[4,5]$. I wonder if there is information available on variant allele frequency in this subset of patients in order to re-analyze the impact of NPM1 and FLT3-ITD on the prognoses of patients following allo-HSCT.
Keywords: Acute myeloid leukemia, Genetic mutations, DNMT3A, FLT3-ITD, NPM1

Anahtar Sözcükler: Akut miyeloid lösemi, Genetik mutasyonlar, DNMT3A, FLT3-ITD, NPM1

Conflict of Interest: The author of this paper has no conflicts of interest, including specific financial interests, relationships, and/or affiliations relevant to the subject matter or materials included.

\section{References}

1. Ardestani MT, Kazemi A, Chahardouli B, Mohammadi S, Nikbakht M, Rostami S, Jalili M, Vaezi M, Alimoghaddam K, Ghavamzadeh A. FLT3-ITD compared with DNMT3A R882 mutation is a more powerful independent inferior prognostic factor in adult acute myeloid leukemia patients after allogeneic hematopoietic stem cell transplantation: a retrospective cohort study. Turk J Hematol 2018;35:158-167.

2. Papaemmanuil E, Gerstung M, Bullinger L, Gaidzik VI, Paschka P, Roberts ND, Potter NE, Heuser M, Thol F, Bolli N, Gundem G, Van Loo P, Martincorena I, Ganly P, Mudie L, McLaren S1, O'Meara S, Raine K, Jones DR, Teague JW, Butler AP, Greaves MF, Ganser A, Döhner K, Schlenk RF, Döhner H, Campbell PJ. Genomic classification and prognosis in acute myeloid leukemia. N Engl J Med 2016;374:2209-2221.

3. Loghavi S, Zuo Z, Ravandi F, Kantarjian HM, Bueso-Ramos C, Zhang L, Singh $R R$, Patel KP, Medeiros $\amalg$, Stingo F, Routbort M, Cortes J, Luthra R, Khoury JD. Clinical features of de novo acute myeloid leukemia with concurrent DNMT3A, FLT3 and NPM1 mutations. J Hematol Oncol 2014;7:74.

4. Kim Y, Lee GD, Park J, Yoon JH, Kim HJ, Min WS, Kim M. Quantitative fragment analysis of FLT3-ITD efficiently identifying poor prognostic group with high mutant allele burden or long ITD length. Blood Cancer J 2015;5:336.

5. Patel SS, Kuo FC, Gibson CJ, Steensma DP, Soiffer RJ, Alyea EP, Chen YA, Fathi AT, Graubert TA, Brunner AM, Wadleigh M, Stone RM, DeAngelo DJ, Nardi V, Hasserjian RP, Weinberg OK. High NPM1-mutant allele burden at diagnosis predicts unfavorable outcomes in de novo AML. Blood 2018;131:2816-2825.

๑Copyright 2019 by Turkish Society of Hematology

Turkish Journal of Hematology, Published by Galenos Publishing House 


\section{Reply to the Authors}

\section{To the Editor,}

We appreciate Dr. Long Su for his interest in our study and his useful comments about our article published in Turkish Journal Hematology, entitled "The impact of DNMT3A/FLT3-ITD/NPM1 on patients with acute myeloid leukemia after allogeneic hematopoietic stem cell transplantation" [1]. Our study demonstrated that DNMT3A R882 mutations are not related to inferior survival in AML patients after allogeneic HSCT. Regarding his comments, we analyzed impact of DNMT3A and FLT3-ITD on NPM1 mutated AML patients. Our finding indicated that considering NPM1 and DNMT3A mutations together, no significant difference in OS and DFS was revealed (Figure 1).

FLT3-ITD mutation had a negative impact on both RFS and OS of patients with mutated NPM1. DFS and OS were significantly more favorable in patients with FLT3-ITD-/NPM1+ compared to patients with other mutation subgroups (Figure 2).

Also, patients with DNMT3A/FLT3-ITD/NPM1 triple mutations demonstrated a significantly worse DFS ( $\mathrm{p}=0.009)$ and $0 \mathrm{~S}(\mathrm{p}=0.028)$ (Figure 3) compared to all other patients (Figure 3).
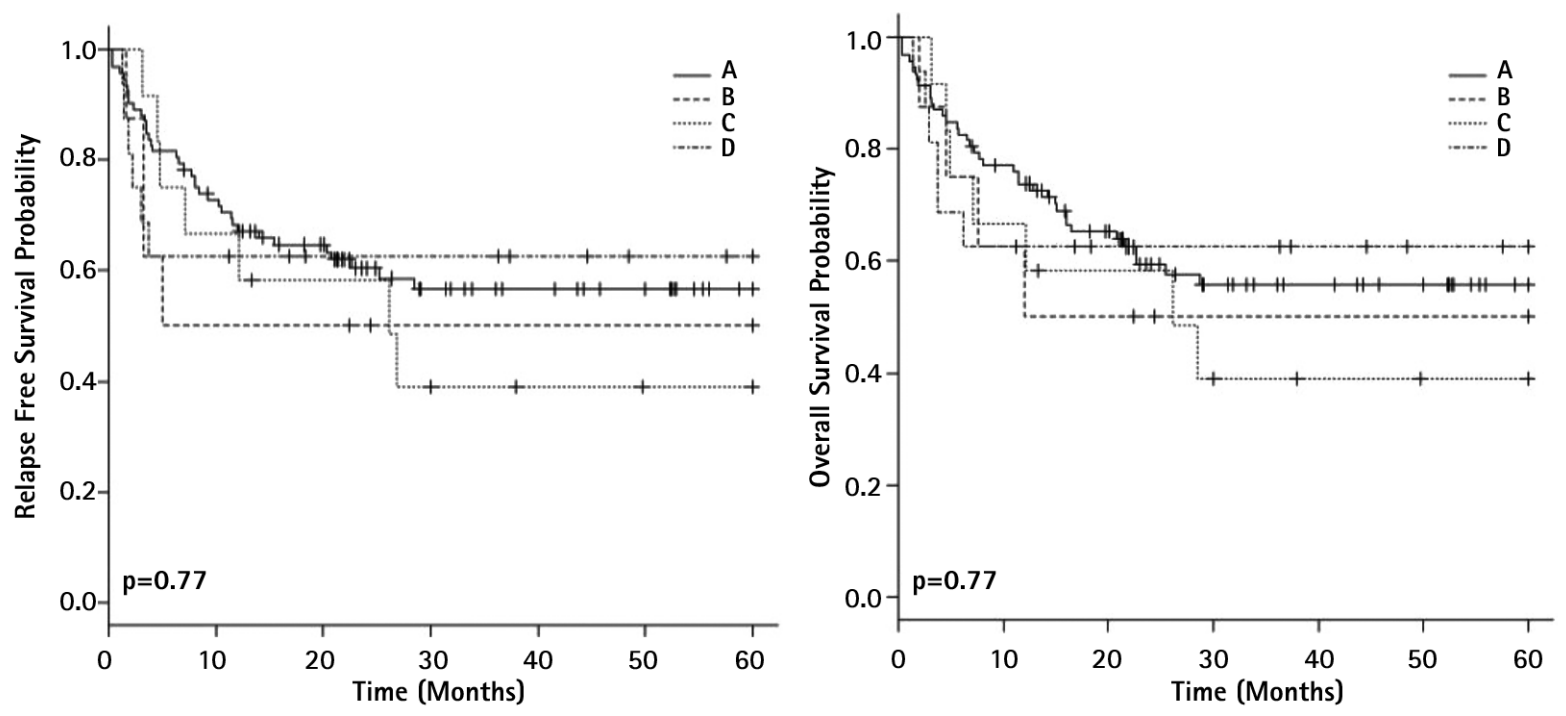

Figure 1. Survival curves of acute myeloid leukemia patients according to mutational status of DNMT3A-/NPM1: relapse free survival (left) and overall survival (right) ( $\mathrm{A}=$ DNMT3A-/NPM1-, $\mathrm{B}=D N M T 3 A+/ N P M 1+, \mathrm{C}=\mathrm{DNMT3A+/NPM1-,} \mathrm{D}=D N M T 3 A-/ N P M 1-)$.
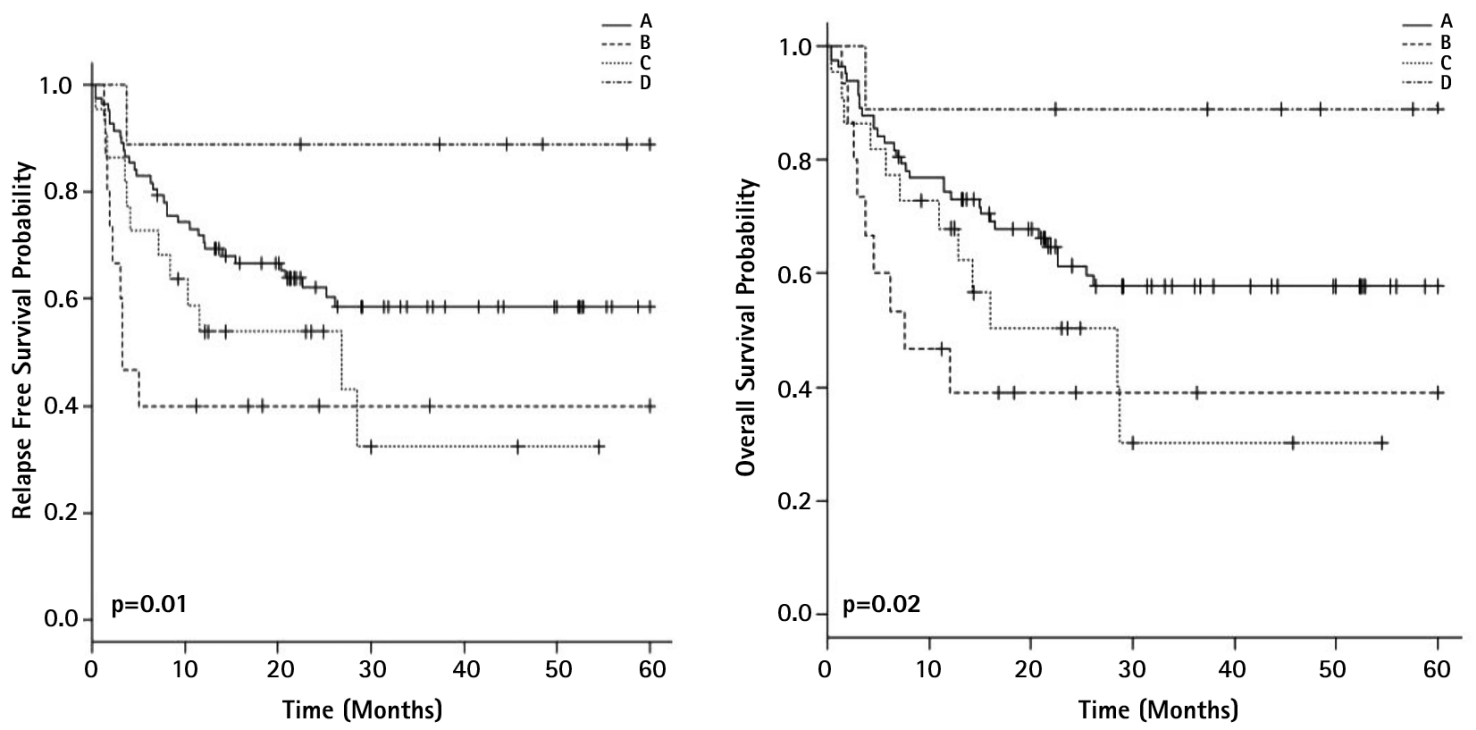

Figure 2. Survival curves of acute myeloid leukemia patients according to mutational status of FLT3-ITD/NPM1: relapse free survival (left) and overall survival (right) ( $\mathrm{A}=$ FLT3-ITD-/NPM1-, $\mathrm{B}=F L T 3-I T D+/ N P M 1+, \mathrm{C}=F L T 3-I T D+/ N P M 1-, \mathrm{D}=F L T 3-I T D-/ N P M 1+)$. 

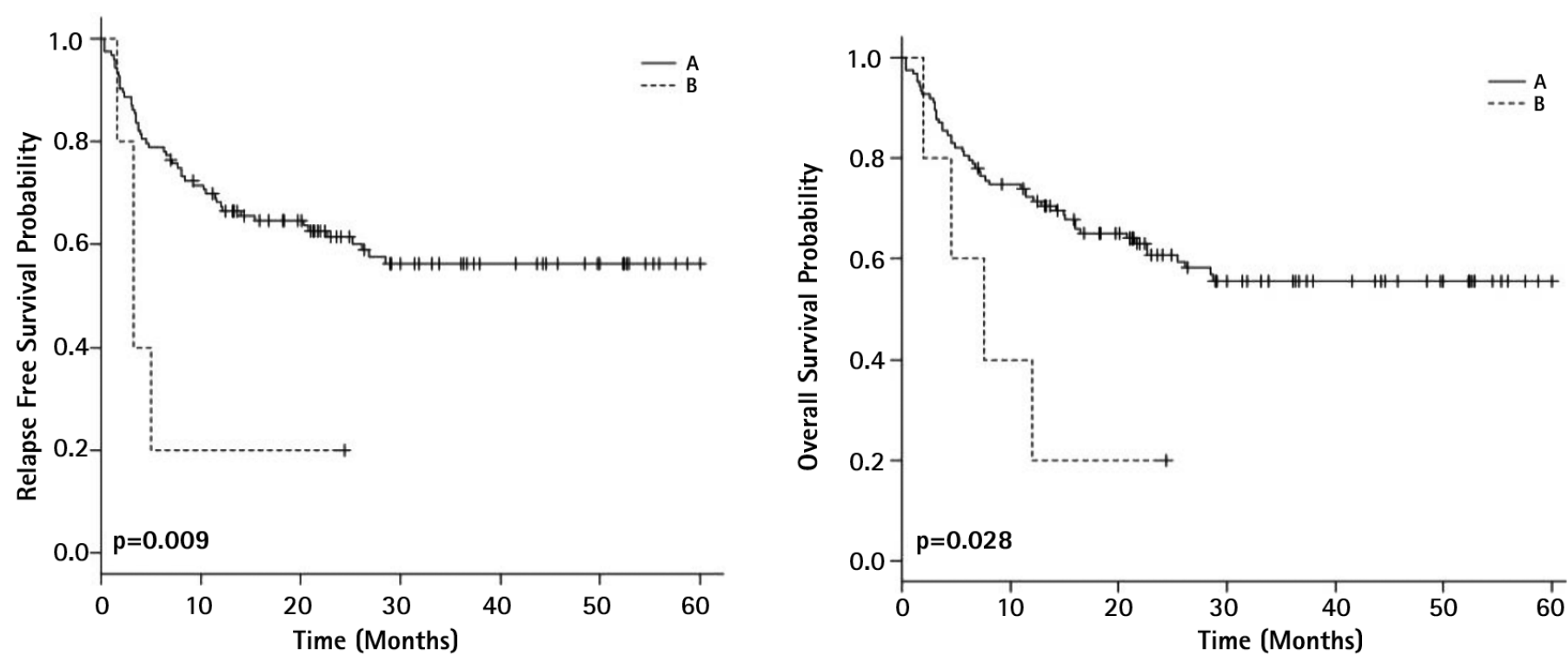

Figure 3. Survival curves of acute myeloid leukemia patients according to DNMT3A/FLT3-ITD/NPM1 triple mutations: relapse free survival (left) and overall survival (right) ( $\mathrm{A}=$ DNMT3A/FLT3-ITD/NPM1, $\mathrm{B}=$ others).

Unfortunately, in this study, information about the allele frequency of mutations was not available for most of patients, but in an ongoing prospective study, we are studying the effect of the allelic frequency of FLT3-ITD and NPM mutations on the clinical outcome of AML patients after HSCT.

Although there is more agreement on the poor prognostic role of DNMT3A mutations in AML patients [2], few studies have been conducted on the effect of these mutations on the clinical outcome of patients after allogeneic transplantation and there are disagreements over the results of these limited studies $[3,4]$.

These differences can be due to coexistence of variable cytogenetic or molecular genetic aberrations in leukemia cells that could be effective in the clinical outcome of the patients. In the present study, only three genetic aberration were tested and additional genetic abnormality might impact the outcome of the patients.

Taken together, our findings indicated that FLT3-ITD may be a more powerful adverse prognostic biomarker than NPM1 and DNMT3A in AML patients after HSCT. Although the comments have allowed us to add useful information to our previous paper, our conclusion remains the same as in our published work.

Best Regards, Bahram Chahardouli, Saeed Mohammadi, Mohsen Nikbakht, Shahrbano Rostami

\section{References}

1. Ardestani MT, Kazemi A, Chahardouli B, Mohammadi S, Nikbakht M, Rostami S, Jalili M, Vaezi M, Alimoghaddam K, Ghavamzadeh A. FLT3-ITD compared with DNMT3A R882 mutation is a more powerful independent inferior prognostic factor in adult acute myeloid leukemia patients after allogeneic hematopoietic stem cell transplantation: a retrospective cohort study. Turk J Hematol 2018;35:158-167.

2. Patkar N, Kodgule R, Kakirde C, Raval G, Bhanshe P, Joshi S, Chaudhary S, Badrinath Y, Ghoghale S, Kadechkar S, Khizer SH, Kannan S, Shetty D, Gokarn A, Punatkar S, Jain H, Bagal B, Menon H, Sengar M, Khattry N, Tembhare P, Subramanian P, Gujral S. Clinical impact of measurable residual disease monitoring by ultradeep next generation sequencing in NPM1 mutated acute myeloid leukemia. Oncotarget 2018;9:36613-36624.

3. Wang H, Chu T, Han SY, Qi JQ, Tang YQ, Qiu HY, Fu CC, Tang XW, Ruan CG, Wu DP, Han Y. FLT3-ITD and CEBPA mutations predict prognosis in acute myelogenous leukemia irrespective of hematopoietic stem cell transplantation. Biol Blood Marrow Transplant 2018 [Epub ahead of print].

4. Yang X, Shi J, Zhang X, Zhang G, Zhang J, Yang S, Wang J, Ke X, Fu L. Biological and clinical influences of NPM1 in acute myeloid leukemia patients with DNMT3A mutations. Cancer Manag Res 2018;10:2489-2497. 